\title{
Association of Heavy School Bags with Musculoskeletal Discomfort among Primary School Children of Islamabad, Pakistan
}

\author{
Humaira Khan ${ }^{1}$, Hadiqa Adnan², Sara Qayyaum³ ${ }^{3}$, Hajar Jamshaid ${ }^{3}$, Rabiya Tahir ${ }^{3}$, Qurat-ul-Ain ${ }^{2}$ \\ ${ }^{1}$ House Officer, Department of Physical Therapy, Islamabad Medical and Dental College, Pakistan \\ ${ }^{2}$ Lecturer, Department of Physical Therapy, Islamabad Medical and Dental College, Pakistan \\ ${ }^{3}$ Ex Student, Doctor of physical Therapy, Shifa Tameer-e-Milat University Islamabad, Pakistan
}

\begin{abstract}
A B S TRACT
Background: Musculoskeletal disorders, an increasing concern among school going children, primarily affect muscles and tendons. They lead to secondary damage to nerves and joints in the neck, upper back, shoulders, arms, and hands, etc. The objective of this study was to determine the association of carrying heavy school bags with musculoskeletal discomfort among primary school children in government schools of Islamabad, Pakistan.

Material and Methods: This cross-sectional survey was conducted in different government schools of Islamabad, Pakistan from June 2018 to November 2018. After an informed consent from parents, 377 healthy school going children aged 6-14 years were included in this study. Data was collected through Backpack Questionnaire. Chi square test was used to compare the frequency of musculoskeletal discomfort with demographic characteristics and backpack-related features. P-value less than .05 was considered statistically significant.

Results: Mean age of the school children was $9.49 \pm 1.53$ years with 179 (46.9\%) male and $203(53.1 \%)$ female students. Majority of students $(89.8 \%)$ were found with school bags more than $15 \%$ of their body weight. Shoulder pain was the most commonly reported complaint (67.3\%). There was a significant association between pain and perceived backpack weight $(P=.001)$, and between pain and self-perceived posture $(P=.001)$. Leaning forward $(66.2 \%)$ was the most commonly adopted posture followed by leaning sideways $(15.4 \%)$ and stooping $(2.9 \%)$, respectively. The association between pain and duration of carrying backpack from home to school was insignificant $(P=.055)$ in contrast to pain and duration of carrying bag from school to home $(P=.007)$, respectively.

Conclusions: Musculoskeletal discomfort was found commonly among primary school children with shoulder pain being the most frequent, as maximum students were carrying heavy school bags.

Key words: Back pain, Musculoskeletal pain, Posture, Primary school children.

\begin{tabular}{|c|c|c|}
\hline Authors' Contribution: & Correspondence: & Article info: \\
\hline${ }^{1}$ Conception; $\quad$ Literature & Hadiqa Adnan & Received: January 21, 2020 \\
\hline $\begin{array}{l}\text { manuscript design and drafting; }{ }^{2,3} \text { Critical } \\
\text { analysis and manuscript review; }{ }^{4-6} \text { Data } \\
\text { analysis; Manuscript Editing. }\end{array}$ & Email:hadiqa.adnan@imdcollege.edu.pk & Accepted: November 10, 2020 \\
\hline
\end{tabular}
\end{abstract}

Cite this article. Khan H, Adnan H, Qayyaum S, Jamshaid H, Tahir R, Qurat-ul-ain. Association of Heavy School Bags with Musculoskeletal Discomfort among Primary School Children of Islamabad, Pakistan. J Islamabad Med Dental Coll. 2021; 10(1): 44-50. Doi:

Funding Source: Nil Conflict of Interest: Nil 10.35787/jimdc.v10i1.492 


\section{Introduction}

The way a society treats its children speaks a lot about its soul. ${ }^{1}$ Children of today are adults of tomorrow. Worldwide there is an increasing concern, about the musculoskeletal health of school going children. ${ }^{2}$ Early morning, it is a common sight to see children going to their schools hunched over due to heavy weight of their school bags. ${ }^{3}$ Musculoskeletal discomfort occurs due to repetitive injury to musculoskeletal system overtime. It primarily affects muscles and tendons and causes secondary damage to nerves and joints in the neck, upper back, shoulders, arms, and hands. ${ }^{4}$ Worldwide more than $90 \%$ of school going children use backpack. Ideal posture is the one in which there is minimum amount of stress and strain and facilitate maximum efficiency of the body. ${ }^{5}$

According to the Bone and Joint Decade, more than 2 million children between the ages of 5 to 14 years are treated yearly for musculoskeletal conditions estimating more than $\$ 7$ billion. ${ }^{6}$ Studies have shown that $10-30 \%$ of Healthy teenage children experience low back pain. ${ }^{4,6} \mathrm{~A}$ study conducted by Talbott et al. in University of Cincinnati College, Cincinnati USA reported pain in $33.5 \%$ of the students, while wearing backpack. ${ }^{7}$

There is evidence that the presence of musculoskeletal disorders (Including neck, shoulder and low back pain) in childhood and adolescence is a significant risk factor for the development of such symptoms in adulthood. ${ }^{8}$ That is why it is important to identify these health problems at an early stage, so that its consequences in later life can be prevented. $^{2}$

Human growth is at a climax during puberty and growth of appendicular skeletal system comes to a halt around 18 years for males and 16 years of age for females. ${ }^{4}$ When wearing backpack, the centre of gravity shifts posteriorly. To compensate for the shift, body leans forward causing muscular distress. This postural shift is likely to cause tissue damage and has been linked with spinal pain. ${ }^{4}$ When the backpack is carried on one shoulder, to achieve a stable position there is a lateral trunk shift. This temporary alteration in the spinal curvature is termed as Functional scoliosis. ${ }^{5}$

Grimmer et al. found notable relationship between the weight of the school bag and forward head posture measured as the CVA (craniovertebral angle). Significant changes were observed in the CVA $\left(5.23^{\circ}\right)$ with a $10 \%$ body weight backpack load among children with complaints of neck pain. ${ }^{9}$

According to American Physical Therapy Association guidelines, weight of the school bag should be 10$15 \%$ of body weight, while the American Academy of Paediatrics approves $10-20 \%$ of bodyweight. ${ }^{10}$ Literature shows that school bags with weight more than $20 \%$ of body weight causes back pain, increased deviation angle of upper body and cardiorespiratory changes. $^{7}$

Studies have proposed that wearing backpack on both shoulders is the safest method and recommend that straps of the school bag should be padded and adjustable according to child's anthropometric measurements. A standard backpack should have chest and waist strap to reduce the force of centre of gravity acting on shoulders. Backpacks with suitable padding decrease the risk of sharp objects poking into the back. Backpack should be at the level of dorsum with adjustable straps fitted tightly. As loose straps can increase the risk of injuries and may lead to kyphosis and lordosis. ${ }^{6}$

This study was designed to explore different features of school bags, methods and duration of 
carriage, self-perceived pain and posture as well as self-perceived weight of the school bag. Contrary to previous researches which were conducted on secondary school students, this study will target the primary school students in government schools of Islamabad, Pakistan. ${ }^{11}$

\section{Material and Methods}

This cross-sectional survey was conducted in different government schools of Islamabad, from June 2018 to November 2018. A sample size of 377 was calculated through Rao software. Nonprobability convenient sampling technique was used to select participants for the study. All healthy primary school children of both genders, aged 6-14 years were included, while children with impaired cognition or any musculoskeletal deformities were excluded from the study. A written informed consent explaining the purpose of the research study, its methodology and agreement for voluntary participation was signed by parents of all the participants. The confidentiality of the acquired data was affirmed on the consent form. Approval from the Federal Directorate of Education, Islamabad was taken to gain access to the different government schools of Islamabad for carrying out this research.

Height and weight of each student, and the weight of full school bag including all additional items brought by the students were measured. The guidelines of American Physical Therapy Association stating that weight of the school bag should be 10$15 \%$ of body weight were followed. Height was measured using measuring tape and body weight was measured using Camry Analog Weight Scale machine.

The questionnaire used in this study was taken from the study by Talbot et al. ${ }^{7}$, a modified version of the survey by Grimmer and William. The original tool collected information on the backpack's characteristics, wear time, after-school activity, medical conditions, and symptoms. The questions were related to backpack characteristics (straps, belts, wheels) and methods of carriage (one shoulder, two shoulders). Self-perceived weight was indicated by students as being light, medium or heavy. The number of times back-pack was carried both to school and from school was used to record carriage times. Posture was assessed by perception of position and the perception of time spent standing upright. There were questions on perception of pain as well. Questionnaire was filled by the researcher on behalf of the children. Data was analysed using SPSS version 21.0. Chi square test was used to compare the frequency of musculoskeletal discomfort with demographic characteristics and backpack-related features. $P$ value less than .05 was considered as statistically significant.

\section{Results}

Of the 377 primary school children included in this study, $46.9 \%(n=179)$ were males and $53.1 \%(n=203)$ females. Mean age of students was $9.49 \pm 1.53$ years with an age range of 6-14 years. Anthropometric measurements of the participants, and school bagrelated parameters are shown in Table I.

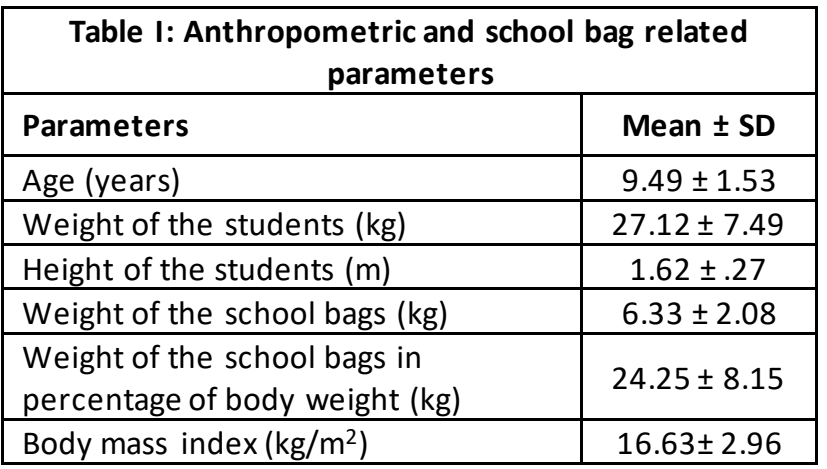

kg-kilogram; m-meter; SD-standard deviation

Almost all of our study participants used backpacks (99.5\%). Various features of backpacks including waist belt, chest strap, wheels, adjustable shoulder 
straps and padded shoulder straps were inquired from children. Among all the characteristics, most commonly used backpack features were adjustable (98.7\%) and padded shoulder straps (91.4\%). Most of our students had school bags with no waist belt (99.5\%) and chest strap (98.2\%).

Majority of the students (83.2\%) in this study carried their bags on both shoulders with only $8.1 \%$ children carrying bags over the right shoulder. When students were asked about the reason for carrying backpacks in a certain way, comfort (74.1\%) and habit (25.9\%) were the more common responses.

Almost half of the students (56.5\%) were always bent-over when carrying their backpacks while $22 \%$ children carried their bags with a straight posture most of the time and only $1.3 \%$ always had a straight posture. Regarding self-perceived posture, leaning forward was the most common response (66.2\%) followed by leaning sideways (15.4\%), while stooping was found in only $2.9 \%$ of the children.

Students were asked to self-rate the weight of the bag. Approximately $59.7 \%$ of the students perceived their backpack weight as heavy, $21.5 \%$ as medium and only $18.8 \%$ as light. Weight of the school bag calculated in percentage of students' body weight is shown in Figure 1. The commonly reported sites of pain are shown in Figure 2.

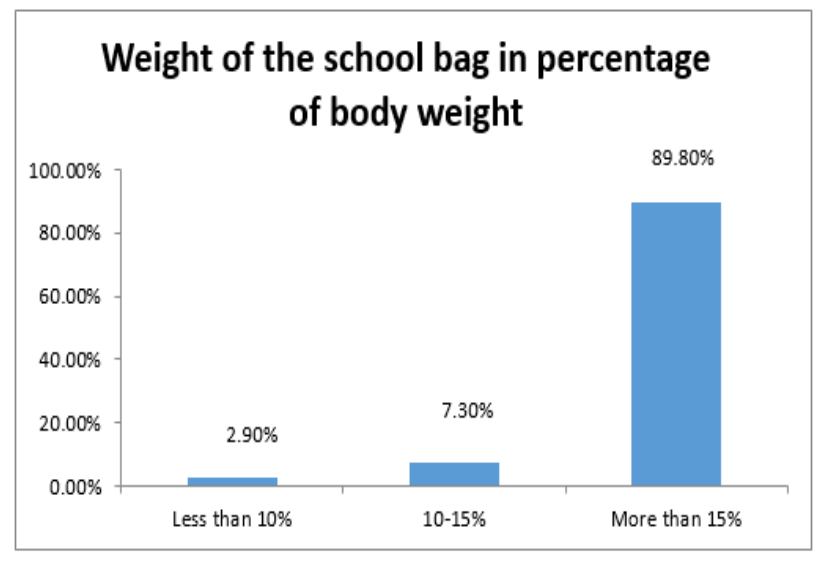

Figure 1: Weight of the school bag in percentage of body weight of the study participants.
For more accurate examination, respondents were also given a checklist to identify any pain experienced due to wearing school bags in areas like upper back, legs, arms and lower back. Both upper (39.8\%) and lower back pain (37.4\%) were reported. Leg pain was also more frequent $(33.8 \%)$ in comparison to arm (18.1\%) and neck pain (17.3\%). Less common symptoms included muscle soreness, tingling in arms and legs and others.

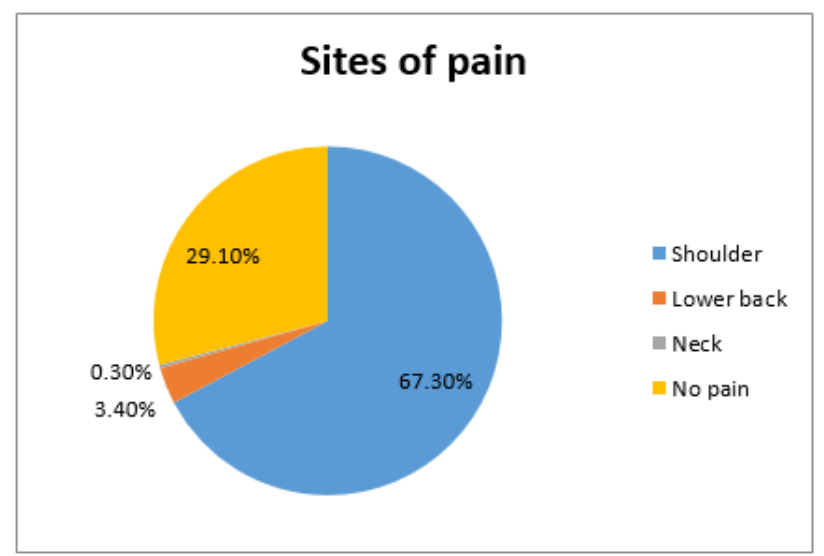

Figure 2: Commonly reported sites for pain

Difference in pain threshold among males and females were also observed. Females (76.35\%) experienced more pain than males (62\%). There was significant association between pain and perceived backpack weight $(P<.001)$ and pain and selfperceived posture $(P<.001)$. The association between pain and duration of carrying backpack from home to school was insignificant $(P=.055)$ in contrast to pain and duration of carrying bag from school to home $(P=.007)$.

\section{Discussion}

In the present study, most of the primary school students reported to have bags with no waist (99.5\%) and chest belt (98.2\%), respectively. These components of a standard backpack help to minimize the forces of gravity. The students were found with heavy backpack mainly because they were carrying too many text books. ${ }^{6}$ Only $2.9 \%$ students in our study had backpacks weighing less 
than $10 \%$ of their bodyweight, $7.3 \%$ had backpacks between $10-15 \%$, while majority (89.8\%) were found with backpacks exceeding $15 \%$ of bodyweight. Similar results were reported in a study by Shahid et al., in which only $7 \%$ students were observed in $10-15 \%$ limit of their body weight. ${ }^{8}$ Wearing backpacks with weight more than $10 \%$ of body weight results in significant postural changes and subjective complaints. Although there is evidence that the use of inclinometer or goniometer is a better tool for posture analysis, but there has been established validity among the children with scoliosis about the perception of the presence or absence of deformities. ${ }^{12}$

Self-perceived posture was evaluated among children and $66.2 \%$ reported leaning forward while wearing backpacks. Similarly, in a study by Rubina et al., 58.5\% of students exhibited forward lean posture while carrying backpacks. Due to the changes in the center of gravity while carrying heavy objects, the body compensates by leaning forward. This postural shift is likely to cause tissue damage and is the reason behind spinal pain. ${ }^{13}$

In this study, $69.6 \%$ of the students reported "yes" to "any pain present at the current time while wearing backpack". Pain is a subjective measure. Perception of pain is a multi-factorial phenomenon and many psychosocial factors are associated with it; for example, time spent watching TV, family history, tight hamstrings and tight quadriceps. ${ }^{6}$ The perception of pain in this study could also be influenced by any one of these factors.

Regarding common sites of pain, $67.3 \%$ reported shoulder pain. This is in contrast to a study by Shahid et al. in which $93.8 \%$ students reported shoulder pain while carrying backpacks. ${ }^{8}$ Our study participants did not report any pain while carrying their bags from home to school, however a significant association was reported on the way back from school to home. This finding has been reported by other studies showing a positive association between duration of carrying school bags and pain. ${ }^{9}$ We also found a significant association between pain and self-rating of the bag and pain with selfperceived posture. Similar results have been reported by Talbott et al. ${ }^{7}$

Gender differences in reporting of pain were also observed in our study with $76.35 \%$ of females and $62 \%$ of males experiencing current pain while carrying their bags. These findings are similar to those documented by Grimmer et al., Dianat et al. and Young et al., suggesting that the recommended weight limit should not be the same for boys and girls. That limit needs to be lower for girls. ${ }^{9,12,14}$

In contrast, Watson et al. showed that mechanical factors (weight of the school bag) are not significantly associated with low back pain in school children, and suggested that psycho-social factors are more important. ${ }^{15}$ Similar results have been reported by Perrone et al., as students carried over $15 \%$ of bag weight which caused biomechanical and physiological adaptations that could increase musculoskeletal injury risk and discomfort. ${ }^{16}$ Batista et al. also found that almost half $(47.7 \%)$ of the students evaluated carried a weight of more than $10 \%$ of their body weight. ${ }^{17}$ The findings by Akbar et el. also shows significant association between perceived bag pack weight and pain, and the pain is essentially higher in females. ${ }^{18}$

Over $70 \%$ of the subjects had a schoolbag that exceeded the recommended $10 \%$ bag weight to body ratio. A total of $32 \%$ of the sample complained of back pain, with $74 \%$ of these defining it as low in intensity. Gender, body mass index (BMI), school and bag weight to body weight ratio was statistically related to back pain. Self-reported back pain in schoolchildren is independently linked to carrying heavy schoolbags. ${ }^{19}$ Growing children are not sufficiently developed in terms of their skeletal and bone structure to tolerate the stress and physical 
demand of carrying a school bag that led to musculoskeletal disorders. ${ }^{20}$ The mean pressure on the body is increased with heavier loads. It is also proposed that with increasing load, there is an increase in the mechanical load and a change in the spatiotemporal parameters of the gait due to carrying the heavy backpack. ${ }^{21}$

\section{Conclusion}

Musculoskeletal discomfort, especially shoulder pain was common among primary school children due to carrying heavy school bags, more than $15 \%$ of their body weight. Gender was an independent factor, but females perceived more pain as compared to males. There was a significant association between pain and perceived backpack weight, self-perceived posture and time duration of carrying bag.

\section{Recommendation}

Weight of the school bag should be strictly limited to $10 \%$ of body weight and backpacks with proper chest and waist straps should be used to reduce compression forces. The students should be guided to wear backpack at the level of dorsum. Seminars should be arranged on the National School Backpack Awareness Day celebrated annually in the third week of September. Students should be allotted lockers by the school and strictly restricted to bring books according to time table.

\section{References}

1. Kesavan A, Jose R, Nithya TC. Overloaded Bags of School Children- a Precursor To "School Bag Syndrome"? NJMDR. 2016; 5(1): 6-11.

2. Rajan $P$, Koti A. Ergonomic assessment and musculoskeletal health of the underprivileged school children in Pune, India. Health Promot Perspect. 2013; 3(1): 36-44. Doi: 10.5681/hpp.2013.005.

3. Khalid F, Amjad F, Ahmad A, Gilani SA, Hanif MK. Frequency of Neck Pain Due to School Bag Usage among Students of Public High Schools in Lahore, Pakistan. Pak Paed J. 2018; 42(3): 207-11.
4. Brzęk A, Dworrak T, Strauss M, Sanchis-Gomar F, Sabbah I, Dworrak B, et al. The weight of pupils' schoolbags in early school age and its influence on body posture. BMC Musculoskelet Disord. 2017; 18(1): 1-11. Doi: 10.1186/s12891-017-1462-z.

5. Kistner F, Fiebert I, Roach K, Moore J. Postural compensations and subjective complaints due to backpack loads and wear time in schoolchildren. Pediatr Phys Ther. 2013; 25(1): 15-24. Doi: 10.1097/PEP.0b013e31827ab2f7.

6. Mohammadi S, Mokhtarinia $H$, Nejatbakhsh $R$, Scuffham A. Ergonomics evaluation of school bags in Tehran female primary school children. Work. 2017; 56(1): 175-81. Doi: 10.3233/WOR-162469.

7. Talbott NR, Bhattacharya A, Davis KG, Shukla R, Levin L. School backpacks: It's more than just a weight problem. Work. 2009; 34(4): 481-94. Doi: 10.3233/WOR-2009-0949.

8. Shahid G, Aziz K, Arif A, Fahim MF. Prevalence of musculoskeletal pain due to heavy backpacks in school going children of Karachi. Int J Phys Med Rehabil. 2018; 6(3): 1000471. Doi: 10.4172/23299096.1000471.

9. Grimmer K, Dansie B, Milanese S, Pirunsan U, Trott P. Adolescent standing postural response to backpack loads: a randomised controlled experimental study. BMC Musculoskeletal Disord. 2002; 3(1): 10. Doi: 10.1186/1471-2474-3-10.

10. Dockrell S, Blake C, Simms C. Guidelines for schoolbag carriage: An appraisal of safe load limits for schoolbag weight and duration of carriage. Work. 2016; 53(3): 679-88. Doi: 10.3233/WOR-162260.

11. Walicka-Cuprÿ̈ K, Skalska-Izdebska R, Rachwał $M$, Truszczyńska A. Influence of the weight of a school backpack on spinal curvature in the sagittal plane of seven-year-old children. Biomed Res Int. 2015: 817913. Doi:10.1155/2015/817913.

12. Dianat I, Javadivala Z, Allahverdipour H. School bag weight and the occurrence of shoulder, hand/wrist and low back symptoms among Iranian elementary schoolchildren. Health Promot Perspect. 2011; 1(1): 76-85. Doi: 10.5681/hpp.2011.008.

13. Khan R, Jabeen H, Arshad HS. Neck, shoulder, and back pain with carrying heavy back packs among the spirit school children in Lahore. IJSR. 2016; 5(6): 397 400.

14. Young IA, Haig AJ, Yamakawa KS. The association between backpack weight and low back pain in children 1. J Back Musculoskelet Rehabil. 2006; 19(1): 25-33. Doi: 10.3233/BMR-2006-19104.

15. Watson KD, Papageorgiou AC, Jones GT, Taylor S, Symmons DP, Silman AJ, et al. Low back pain in schoolchildren: the role of mechanical and 
psychosocial factors. Arch Dis Child. 2003; 88(1): $12-7$. Doi: 10.1136/adc.88.1.12.

16. Perrone M, Orr R, Hing W, Milne N, Pope R. The Impact of Backpack Loads on School Children: A Critical Narrative Review. Int J Environ Res Public Health. 2018; 15: 2529. Doi: 10.3390/ije rph15112529.

17. Batista ITS, de Melo-Marins D, da Silva Carvalho RG, Lara Elena Gomes LE. Weight and mode of carrying schoolbags at elementary school: effect of the school grades and sex. Fisioter Pesqui. 2016; 23(2): 210-5. Doi: 10.1590/1809-2950/15376823022016.

18. Akbar F, AlBesharah M, Al-Baghli J, Bulbul F, Mohammad D, Qadoura B, et al. Prevalence of low Back pain among adolescents in relation to the weight of school bags. BMC Musculoskelet Disord. 2019; 20: 37. Doi: 10.1186/s12891-019-2398-2.
19. Spiteri K, Busuttil M-L, Aquilina S, Gauci D, Camilleri E, Grech V. Schoolbags and back pain in children between 8 and 13 years: a national study. Br J Pain. 2017; 11(2): 81-6. Doi:10.1177/2049463717695144.

20. Nazari M, Beigi R, Salesi M, Cousins R, Mokarami H. Development and validation of the tool for the evaluation of the behavioral factors affecting the prevalence of musculoskeletal disorders in Iranian students. BMC Pediatr. 2020; 20: 551. Doi: 10.1186/s12887-020-02452-8.

21. Ahmad HN, Barbosa TM. The effects of backpack carriage on gait kinematics and kinetics of schoolchildren. Sci Rep. 2019; 9: 3364. Doi: 10.1038/s41598-019-40076-w. 